Print ISSN: 2233-4165 / Online ISSN 2233-5382

doi:http://dx.doi.org/10.13106/jidb.2020.vol11.no4.31

\title{
A Study on the Feasibility of Win-Win Growth in Wholesale Market*
}

\author{
Jong-Moon WON**
}

Received: March 09, 2020. Revised: March 15 2020. Accepted: April 05, 2020.

\begin{abstract}
Purpose: At a time when the distribution industry is dominated by capital and technology, win-win growth among businesses groups (BGs) in wholesale market is becoming a social issue. Therefore, through analysis of market growth, market concentration (MC) and market power (MP), we want to identify the structure of the wholesale market and the competitiveness of the BGs in terms of market share (MS), sales-profit ratio (SPR), and labor productivity (LP) to explore the possibility of win-win growth. Market situation: Wholesale and Retail sales ratio (W/S) continues to increase, which also means inefficiency in distribution channels or opportunities in wholesale markets. Wholesale sales have grown 8.3 percent annually over the past 15 years, while the number of companies and workers has declined since 2017, which is why some restructuring is believed to begin in the wholesale industry. In terms of MC and MP, the growth potential of SBG can be found in FCB, ARM, FBT and CME BTs. Methodology and data: Through ANOVA and Regression Analysis, the 2015 Economic Census Data of KOSTAT was analyzed. Results: The results of ANOVA show that statistically significant SBG has a larger MS than LBG. The SPR was not different among BGs. LP is higher for LBG than for other BGs. Regression results show that the employment weight (EW) and the company size (SC) have positive effects on the MS, but the company weight (CW) and employment size (SE) have negative effects. In the case of SPR, the CW is positive and the EW is negative. In addition, LP appears to be more positive as SC in the BGs is larger. Conclusions: Although there is sufficient potential for SBG in the wholesale market, there is a problem that needs to increase LP. Therefore, the SBG needs to restructure in terms of number of companies and SC to improve the efficiency of employment. In terms of MC and MP, the SBG looks for possibilities in FCB, ARM, FBT and CME BTs. In addition, SBG that seeks higher returns with human services rather than simple sales is found to be competitive in the HHG, MES and CME BTs.
\end{abstract}

Keywords: Wholesale Market, Market Dominance, Financial Performance, Win-win Growth, Competitiveness

JEL Classification Code: C12, D40, L81

\section{1. 서론}

1996 년 유통시장 개방 후 국내:외 유통기업들의 대규모 자본과 선진 경영기법 그리고 유통산업 선진화라는 정책적 목표를 설정한 정부의 법·제도적 지원을 바탕으로 소매시장의 구조는 소규모 자영업 중심에서 대형유통기업 중심으로 완전히 재편되었다. 급속히 쇠락해 가는 중소유통업체의 경쟁력 강화를 위한 재정지원 사업은 효율성에 있어 다양한 의견이 존재하고 (Choi \& Suh, 2017), 대형유통기업에 대한 영업시간 규제와 2 일 의무휴업제 그리고 신규 출점을 제한하는

*This study was supported by research year program of Namseoul University.

**First Author and Corresponding Author:Professor, Department of Global Marketing and Distribution, Namseoul University,

ChungNam-Do, Republic of Korea, Email:jmwon@nsu.ac.kr ๑ Copyright: Korean Distribution Science Association (KODISA)

This is an Open Access article distributed under the terms of the Creative Commons Atribution NonCommercial License (https://rreativecommons.orglicenses/by-ncl4.0/ which permits unrestricted non-
사업조정제도는 중소유통업체를 위한 정책적 효과에 의문이 제기되기도 한다 (Kim \& Kwon, 2013). 향후 4 차 산업 기술혁명이 유통산업에 접목된 후, 기술기반 유통기업들이 적극적으로 시장에 진입하면 유통시장에 또 한번의 큰 변혁의 원인이 될 것으로 판단된다 (Lee \& Lim, 2020). 반면에 도매시장은 특정한 자본이나 기술에 의해 주도되지 않고 아직은 유통경로상에서 서비스 기반의 대·중소 업체들이 상호 공존하는 시장으로 남아있다 $(\mathrm{Im}, \mathrm{Kim}, \&$ Yang, 2017). 다만 프랜차이즈 가맹사업, 도·소매를 겸하는 창고형 할인매장(MWC, 소규모 점포를 관리하는 임의가맹형 체인사업(Voluntary chain)과 상품공급업, 제조업 중심의 식자재 공급업 그리고 소모성 자재를 취급하는 $\mathrm{MRO}$ 등이 자본을 기반으로 도매시장에 진출한 상황이다 (Won, 2010). 유통산업의 혁신이 소매업 중심으로 이루어졌기 때문에 도매업이 상대적으로 낙후되었거나 관심 밖의 영역이었을 수도 있다. 자영업 또는 소기업들의 생존을 위해 생계형 적합업종 지정이 법제화되고 기존 중소기업 적합업종 재지정(Ministry of SMEs and Startups, 2018)등이 
쟁점화 되고 있는 시점에, 일부 도매업종이 적합업종으로 지정되면 자영업 혹은 중소업체가 경쟁력을 가지고 구조적으로 자리매김 할 수 있는지 가능성을 분석해 봄은 의미있는 정책 연구가 될 것으로 판단된다. 이 논문에서는 현 도매시장의 현황과 구조를 시장집중도와 시장지배력을 통해 분석하고, 대·중소 도매업의 경쟁력 정도를 시장점유율, 매출수익율, 그리고 노동생산성의 관점에서 파악해 보고자 한다.

\section{2. 이론적 배경}

\section{1. 선행연구}

\subsection{1 시장의 지배구조와 영향}

모든 시장의 지배구조는 구매자의 선택에 의해 결정되는데, 미국의 도매시장은 새롭게 출현하는 혁신적인 도매업태에 의해 지배되어 왔고 (Pirog \& Smith, 1996, 한국의 화장품 시장도 마찬가지로 소비자가 쇼핑할 때의 필요를 가장 잘 충족시킬 수 있는 소매업태에 의해 시장이 성장해 오고 있다 (Yoon, Song, \& Kang, 2020). 또한 시장의 집중도는 대·중소 기업간의 협력을 통해 영향을 받을 수 있는데, 유럽 5 개국 이동통신 도매시장의 경우 이동통산망사업자(MNO)간의 시장점유율은 변하지 않았지만, 가상이동통신망사업자(MVNO)를 경쟁적으로 유치함으로 그들의 시장집중도는 낮아진 것으로 나타났다 (Gamido \& Whalley, 2013). 시장 지배구조의 변화는 업태의 효율성과 유통경로상의 파워이동 그리고 새로운 제도 도입 등에 의해서 결정된다고 할 수 있다 (Quinn \& Leavy, 2005). 이와 같은 시장지배력은 가격상승의 요인이 될 수 있는데, 인도의 전기도매시장에서 특정 기업의 높은 시장지배력이 일정부분 가격 상승요인이 되었다는 연구결과도 있다 (Shukla \& Thampy, 2011). 불완전 경쟁시장의 경우 정부는 정책적으로 일부분 시장에 개입하여 경쟁을 통한 가격 안정과 효율적인 시장으로의 전환을 유도할 필요가 있다.

\subsection{2 정부규제효과}

시장이 효율적으로 작동되는 경우 정부의 개입은 도리어 시장을 위축시키고 경제적 후생을 감소시킬 수도 있다. 미국 뉴욕 택시 시장의 규제는 택시 메달리온 가격을 상승시키고 이는 결과적으로 택시요금 상승의 요인이 될 것으로 분석되었다 (Cetin \& Enjigit, 2013). 중소 소매점 보호를 위한 대형마트 규제는 사회적 비용 감소차원의 긍정적인 면과 더불어 시장의 효율성에 대한 문제가 제기되기도 한다. 또한 대형마트 규제는 타 산업으로의 파급효과, 즉 대형마트에 납품하는 농수산물의 경우 매출이 줄고 도매가격이 하락할 뿐만 아니라 실제 고용에도
타격을 받고 있다는 연구결과도 있다 (Kim \& Ryu, 2014). 반면에 대·중소 업체가 상생하는 시장을 유도하기 위해 전통시장에 대한 정부의 지원은 효과적이지만, 영세상인의 수가 과도하게 많은 경우 그 효과가 반감하는 것으로 나타난다 (Lee, 2019). 정부의 시장개입의 효과는 크기와 방향에 있어 다양하게 나타나는데, 기업군 간의 동반성장을 촉진하여 시장집중도를 낮추고 기업군 내의 과도한 경쟁을 완화하여 업체들의 경쟁력을 확보할 수 있다면 효율적인 시장환경을 조성할 수 있을 것이다.

\section{2. 도매업의 현황과 구조}

\section{1 분석변수와 분석범위}

도매시장의 분석범위는 종사자 수로 구분된 9 개의 기업군(bgs; $\mathrm{k}=1 \sim 9)$ 을 Table 1 과 같이 3 개(SBG, MBG, \& LBG)의 기업군(BGs)으로 축약하고, 업종은 도매업 전체(WTC)와 8 개의 업종(BT)으로 구분하여 분석한다. 기업군의 도매업 성과 분석은 시장점유율( $(\mathrm{MS}$ ), 매출수익율(SPR)과 노동생산성( $(\mathrm{P})$ 지표를 사용하고, 시장지배력은 통계자료의 한계로 말미암아 시장집중도(MC)와 허핀달지수( $(\mathbb{m})$ 의 개념을 아래의 수식과 같이 변형하여 사용하고자 한다. 특정집단의 시장집중도는 그 집단의 시장점유율을 합하여 산정함으로 집단의 시장내 영향력은 측정할 수 있으나, 기타 기업이나 집단에 대한 정보가 없는 단점이 있다. 허핀달지수는 산업내 모든 기업의 시장점유 백분율의 제곱의 합으로 산정함으로 시장내 경쟁 혹은 지배정도를 파악할 수 있다 (Garido \& Whalley, 2013; Shukla \& Thampy, 2011). 본 연구에서는 시장집중도 산정을 위해 특정 기업군의 시장점유율(MC1)과 기업군내 경쟁정도를 동시에 파악하기 위하여 시장점유율을 업체 수 비중으로 나눈 $\mathrm{MC}$ 값을 비교하여 분석한다. 또한 허핀달지수를 산정하기 위해 개별 기업의 시장점유율을 사용해야 하지만 본 연구 통계자료는 기업군에 대한 정보만 가능함으로 기업군의 시장점유율을 사업체 수로 나눈 값을 활용하여 $\mathrm{HL}$ 를 산정하고 기업군의 시장점율로만 산정한 $\mathrm{H} 11$ 과 비교분석 하였다.

$$
\begin{aligned}
M C 1_{i j} & =\left(\sum_{k=3 j-2}^{3 j} m s_{k i}\right)_{j} \\
M C 2_{i j} & =\left(\sum_{k=3 j-2}^{3 j}\left(m s_{k i} / c w_{k i}\right)\right)_{j} \\
H I 1_{i j} & =\left(\sum_{k=3 j-2}^{3 j}\left(m s_{k i}^{2}\right)_{j}\right.
\end{aligned}
$$




$$
H I 2_{i j}=\left(\sum_{k=3 j-2}^{3 j}\left(\frac{m s_{k i}}{c o_{k i}}\right)^{2} \times c o_{k i}\right)_{j}
$$

Where, $i=8$ BTs, $j=3$ BGs \& $k=9$ bgs

MS: Market Share by 3 BGs, ms: market share by 9 bgs

$\mathrm{CW}$ : percent of number of companies

CO: company numbers

Table 1: Variables and Definitions

\begin{tabular}{|c|c|c|c|}
\hline Classification & \multicolumn{2}{|c|}{ Variables } & Definitions \\
\hline \multirow{3}{*}{$\begin{array}{c}\text { Business } \\
\text { Groups (BGs) }\end{array}$} & \multicolumn{2}{|c|}{$\begin{array}{l}\text { Small Business } \\
\text { group (SBG) }\end{array}$} & $\begin{array}{l}\text { worker \# 1-9 or Sales volume } 5 \\
\text { Bill. won below. } \Sigma \text { bgs }(1,2,3)\end{array}$ \\
\hline & \multicolumn{2}{|c|}{$\begin{array}{l}\text { Medium Business } \\
\text { Group (MBG) }\end{array}$} & $\begin{array}{c}\text { worker \# 10-99 or Sales volume } \\
100 \text { Bill. won below. } \Sigma \text { bgs }(4,5,6)\end{array}$ \\
\hline & \multicolumn{2}{|c|}{$\begin{array}{l}\text { Large Business } \\
\text { Group (LBG) }\end{array}$} & $\begin{array}{c}\text { worker \# } 100 \text { above or Sales } \\
\text { volume } 100 \text { Bill. won above. } \\
\qquad \operatorname{Lbgs}(7,8,9)\end{array}$ \\
\hline \multirow{9}{*}{$\begin{array}{l}\text { Wholesale } \\
\text { Business } \\
\text { Types (BTs) }\end{array}$} & WTC & \multicolumn{2}{|c|}{$\begin{array}{l}\text { Wholesale Trade and Commission Trade, } \\
\text { Except of Motor Vehicles and Motorcycles }\end{array}$} \\
\hline & FCB & \multicolumn{2}{|c|}{ Wholesale on a Fee or Contract Basis } \\
\hline & ARM & \multicolumn{2}{|c|}{$\begin{array}{l}\text { Wholesale of Agricultural Raw Materials and } \\
\text { Live Animals }\end{array}$} \\
\hline & FBT & \multicolumn{2}{|c|}{ Wholesale of Food, Beverages and Tobaccos } \\
\hline & HHG & \multicolumn{2}{|c|}{ Wholesale of Household Goods } \\
\hline & MES & \multicolumn{2}{|c|}{$\begin{array}{l}\text { Wholesale of Machinery Equipment and } \\
\text { Supplies }\end{array}$} \\
\hline & CME & \multicolumn{2}{|c|}{$\begin{array}{c}\text { Wholesale of Construction Materials, } \\
\text { Hardware and Heating and Air Conditioning } \\
\text { Equipment }\end{array}$} \\
\hline & OSW & \multicolumn{2}{|r|}{ Other Specialized Wholesale } \\
\hline & NSG & \multicolumn{2}{|c|}{ Wholesale of Non-Specialized Goods } \\
\hline \multirow{3}{*}{$\begin{array}{l}\text { Performance } \\
\text { Measure }\end{array}$} & \multicolumn{2}{|c|}{ Market share (MS) } & sales volume $/ \Sigma$ sales volume \\
\hline & \multicolumn{2}{|c|}{$\begin{array}{l}\text { Sale-profit ratio } \\
\text { (SPR) }\end{array}$} & profit / sales volume \\
\hline & \multicolumn{2}{|c|}{$\begin{array}{l}\text { Labor productivity } \\
\text { (LP) }\end{array}$} & sales volume / number of workers \\
\hline \multirow{4}{*}{$\begin{array}{l}\text { Market } \\
\text { Dominance } \\
\text { Index }\end{array}$} & \multicolumn{2}{|c|}{$\mathrm{MC1}$} & $\begin{array}{c}\text { Market concentration } 1: \\
\Sigma(\mathrm{ms} \text { of bgs) by BGs and BTs }\end{array}$ \\
\hline & \multicolumn{2}{|c|}{ MC2 } & $\begin{array}{c}\text { Market concentration 2: } \\
\Sigma(\mathrm{ms} / \mathrm{cw} \text { of bgs }) \text { by BGs and BTs }\end{array}$ \\
\hline & \multicolumn{2}{|c|}{$\begin{array}{l}\text { HerfindahlIndex1: } \\
\text { HI1 }\end{array}$} & $\Sigma(\mathrm{ms} \text { of bgs })^{2}$ by BGs and BTs \\
\hline & \multicolumn{2}{|c|}{$\begin{array}{l}\text { Herfindahl Index } 2 \text { : } \\
\quad \text { HI2 }\end{array}$} & $\begin{array}{c}\Sigma\left((\mathrm{ms} / \mathrm{co} \text { of bgs })^{2} \mathrm{xco}\right) \text { by BGs } \\
\text { and BTs }\end{array}$ \\
\hline
\end{tabular}

\subsection{2. 유통경로와 도매업}

소매업태의 경쟁력은 유통경로의 경쟁력과 무관하지 않다. 그러므로 유통경로 설계 및 관리 능력이 매우 중요하고 효율적인 중간상의 역할과 기능이 그 한 부분이 될 수 있다 (Quinn \& Murray, 2005). 기업형 체인스토어와 가맹형 프랜차이즈 형태의 수직적 유통경로시스템
VDCS)은 관리 측면의 효율화를 이루고 있고, 특히 가맹점과 가맹 본부간의 상생 계약의 움직임은 소규모 점포 가맹점에게 생존의 기회가 될 수 있다 (Park, Kim, \& Yu, 2018; Yang \& Ju, 2011). 유통경로 설계는 경로유형, 커버리지 그리고 중간상 선정 등을 고려해야 하는데, 유통경로의 길이를 나타내는 경로유형이 도매시장의 크기를 결정지을 수 있다. 이는 경로를 통해 요구되는 소비자의 욕구, 경제성, 통제가능성, 취급되는 상품의 특성, 거래되는 시장의 특성 그리고 중간상의 특성이 반영되어 결정된다. 경로유형을 측정하기 위해 도매매출을 소매매출로 나눈 W/R 비율을 사용하기도 하는데, 이 값이 1 이면 도매업을 한 단계 거쳐 소매업에 유통되는 것을 의미하며 2 에 가까우면 두 단계를 거치는 것을 의미한다. 이 비율이 2000 년 1.316 에서 2010 년 1.558 을 거쳐 2015 년에는 2.045 로 점점 상승하고 있는데, 이는 선진국에 비하여 유통경로가 길거나 더 많은 단계를 거쳐 상품이 소비자에게 판매됨을 의미한다. 이는 유통경로의 비효율성 혹은 동시에 도매시장의 기회의 의미로 평가하기도 한다.

Table 2: Changes in Wholesale-Retail Sales Ratio

(unit: billions of won)

\begin{tabular}{|c|r|r|r|r|r|}
\hline Classification & $\mathbf{2 0 0 0 y r}$ & $\mathbf{2 0 0 5 y r}$ & $\mathbf{2 0 1 0 y r}$ & $\mathbf{2 0 1 5 y r}$ & \multicolumn{1}{c|}{$\mathbf{2 0 1 7 y r}$} \\
\hline Wholesale (A) & 210,055 & 292,742 & 499,367 & 693,111 & 770,080 \\
\hline Retail (B) & 159,610 & 207,039 & 320,462 & 338,985 & 381,559 \\
\hline W/R ratio (A/B) & 1.316 & 1.414 & 1.558 & 2.045 & 2.020 \\
\hline
\end{tabular}

\section{3. 도매시장의 구성과 변화}

도매업의 매출규모는 2000 년에서 2015 년까지 15 년간 연평균 $83 \%$ 성장한 반면에 업체 수와 근로자 수는 연평균 3\%대 성장에 그쳐 사업의 규모화를 통하여 도매업체 운영의 효율성이 개선되고 있는 것 같다.

Table 3: Changes in the Composition of the Wholesale Business (unit: billions of won, com., person, \%)

\begin{tabular}{|c|r|r|r|r|r|r|}
\hline Classification & $\mathbf{2 0 0 0 y r}$ & $\mathbf{2 0 0 5 y r}$ & $\mathbf{2 0 1 0 y r}$ & $\mathbf{2 0 1 5 y r}$ & $\mathbf{2 0 1 7 y r}$ & $\begin{array}{c}\text { CAGR } \\
\text { ('00 '15) }\end{array}$ \\
\hline $\begin{array}{c}\text { Sales volume } \\
\text { (A) }\end{array}$ & 210,055 & 292,742 & 499,367 & 693,114 & 770,080 & $8.3 \%$ \\
\hline $\begin{array}{c}\text { \# of } \\
\text { company (B) }\end{array}$ & 189,452 & 207,211 & 236,289 & 324,765 & 320,770 & $3.7 \%$ \\
\hline $\begin{array}{c}\# \text { of workers } \\
\text { (C) }\end{array}$ & 798,471 & 848,961 & 995.352 & $1,284,482$ & $1,269,734$ & $3.2 \%$ \\
\hline $\begin{array}{c}\text { Sales/compa } \\
\text { ny (A/B) }\end{array}$ & 1,109 & 1,413 & 2,113 & 2,134 & 2,400 & $4.5 \%$ \\
\hline $\begin{array}{c}\text { Sales/worker } \\
\text { (A/C) }\end{array}$ & 263 & 345 & 502 & 540 & 606 & $4.9 \%$ \\
\hline
\end{tabular}

Note: Compound Annual Growth Rate (CAGR)

또한 지속적으로 증가해 오던 도매업 내 업체 수와 근로자 수가 2017 년에는 감소하는 것으로 보아 도매업계에도 다소간의 구조조정이 
시작되는 것으로도 판단된다. 결과적으로 업체당 매출과 근로자 인당 매출은 지속적으로 증가하는 것으로 나타난다.

\subsection{4. 도매업의 성과분석}

전체 도매업의 근로자 1 인당 매출은 대기업군(BG)이 소기업군(BBG)의 약 2.9 배로 나타나고 있으나, 업종별(BTs)로 보면 $\mathrm{FCB}$ (상품 중개업), ARM(산업용 농축산물 및 동.식물 도매업), $\mathrm{FBT}($ 음식료품 및 담배 도매업), $\mathrm{CME}$ (건축자재, 철물 및 난방장치 도매업)의 경우 대기업군과 소기업군과의 인당 매출의 차이가 적고, 반면에 OSW(기타 전문 도매업), NSG(상품 종합 도매업) 경우 그 차이가 매우 큰 것으로 나타나고 있다. 매출수익율의 경우 도매업 전체로서는 소기업군이 상대적으로 대기업군보다 높은 것으로 나타나지만 FCB, FBT, CME 와 OSW 경우 대기업군의 매출수익율이 소기업군에 비해 상대적으로 높다. 그러나 소기업군의 HHG(생활용품 도매업), $\mathrm{MES}$ (기계장비 및 관련 물품 도매업), $\mathrm{CME}$ 업종에서의 매출수익율이 $5 \%$ 를 상회할 뿐만 아니라 대기업군과도 비교하여 상대적으로 높게 나타나 소기업군에게 경쟁력이 있는 도매업종이라 할 수 있다. 이는 상품 판매뿐만 아니라 인적서비스를 필요로 하는 업종이기 때문으로 매출수익율이 상대적으로 높은 것으로 해석될 수 있다. 업체당 그리고 고용인당 수익은 대기업군이 규모의 경제를 이루어 소기업군에 비해 월등히 높은 것으로 분석되고 있으나, 소기업군은 MES, CME, 그리고 OSW 업종에서 타 업종에 비해 상대적으로 매출수익 및 고용인당 수익이 다소 높은 편으로 나타난다.

Table 4: Selected Financial Ratios in Wholesale Business (unit: millions of won, \%)

\begin{tabular}{|l|r|r|r|r|r|r|r|r|}
\hline $\begin{array}{l}\text { WS } \\
\text { Biz. } \\
\text { Type }\end{array}$ & \multicolumn{2}{|c|}{$\begin{array}{c}\text { Sale } \\
\text { per worker }\end{array}$} & \multicolumn{2}{c|}{$\begin{array}{c}\text { Sales-profit } \\
\text { R. }\end{array}$} & \multicolumn{2}{c|}{$\begin{array}{c}\text { Profit } \\
\text { per company }\end{array}$} & \multicolumn{2}{c|}{$\begin{array}{c}\text { Profit } \\
\text { per worker }\end{array}$} \\
\cline { 2 - 9 } SBG & LBG & SBG & LBG & SBG & LBG & SBG & LBG \\
\hline WTC & 395 & 1,150 & 4.6 & 3.8 & 46 & 9,620 & 18.2 & 43.8 \\
\hline FCB & 413 & 560 & 4.6 & 10.9 & 47 & 6,216 & 18.9 & 60.9 \\
\hline ARM & 328 & 486 & 4.5 & 3.8 & 35 & 2,014 & 14.8 & 18.5 \\
\hline FBT & 445 & 500 & 3.5 & 5.4 & 40 & 5,222 & 15.6 & 27.2 \\
\hline HHG & 272 & 735 & 6.2 & 5.0 & 41 & 8,374 & 16.9 & 36.6 \\
\hline MES & 355 & 793 & 5.7 & 3.0 & 53 & 4,838 & 20.3 & 23.5 \\
\hline CME & 340 & 393 & 6.0 & 7.3 & 53 & 3,902 & 20.3 & 28.5 \\
\hline OSW & 564 & 3,070 & 3.6 & 4.3 & 53 & 33,680 & 20.4 & 131.8 \\
\hline NSG & 498 & 3,551 & 3.4 & 2.3 & 45 & 27,878 & 17.1 & 80.4 \\
\hline
\end{tabular}

\section{2. 도매시장 집중도와 지배력}

도매시장의 집중도를 나타내는 시장점유율 (MC1)을 보면 NSG 업종을 제외하고는 대부분 중소기업군에 의해 시장이 집중되고 있는 것으로
나타난다. 전체 도매시장의 $44 \%$ 는 소기업군, $35 \%$ 는 중기업군 그리고 $21 \%$ 만이 대기업군에 의해 시장 매출이 일어나고 있다. 반면에 기업군내 업체 수를 반영한 $\mathrm{MC}$ 를 보면 소기업군은 $\mathrm{MC1}$ 과 비교하여 큰 차이가 없으나 대기업군은 크게 증가한다. 이는 소기업군에 속하는 업체 수의 과다로 시장 구조적인 관점에서 업체간 경쟁이 치열하고 규모의 경제 관점에서 경쟁력이 없는 것으로 분석된다. 반면에 대기업군은 소수의 대기업이 도매시장 일정부분을 점유하고 있고 특히 OSW 업종 경우에는 그 집중도가 매우 높은 것으로 나타난다. 2015 년 자료에 의하면 일정부분 도매시장은 아직도 다수의 소기업에 의해 움직이고 있음을 볼 수 있다.

Table 5: Wholesale Market Concentration ratio

(unit: ratio)

\begin{tabular}{|c|c|c|c|c|c|c|}
\hline \multirow{2}{*}{$\begin{array}{l}\text { WS Biz. } \\
\text { Type }\end{array}$} & \multicolumn{3}{|c|}{ MC1 by Biz. Group } & \multicolumn{3}{c|}{ MC2 by Biz. Group } \\
\cline { 2 - 7 } & SBG & MBG & LBG & SBG & MBG & LBG \\
\hline WCT & 0.44 & 0.35 & 0.21 & 0.47 & 6.00 & 118.76 \\
\hline FCB & 0.54 & 0.42 & 0.04 & 0.58 & 6.44 & 32.09 \\
\hline ARM & 0.66 & 0.31 & 0.03 & 0.68 & 9.40 & 46.93 \\
\hline FBT & 0.58 & 0.36 & 0.07 & 0.62 & 5.12 & 52.14 \\
\hline HHG & 0.31 & 042 & 0.26 & 0.33 & 6.85 & 86.42 \\
\hline MES & 0.43 & 0.40 & 0.17 & 0.47 & 5.72 & 80.95 \\
\hline CME & 0.73 & 0.25 & 0.02 & 0.74 & 7.22 & 45.32 \\
\hline OSW & 0.47 & 0.35 & 0.18 & 0.49 & 7.76 & 264.43 \\
\hline NSG & 0.06 & 0.10 & 0.84 & 0.06 & 1.06 & 59.24 \\
\hline
\end{tabular}

Note: $\mathrm{MCl}=\Sigma(\mathrm{ms}$ of bgs) by BGs and BTs

$\mathrm{MC} 2=\Sigma(\mathrm{ms} / \mathrm{cw}$ of bgs $)$ by BGs and BTs

도매시장의 지배력을 분석하기 위하여 허핀달지수 개념을 활용하여 도매 업종(BTs)과 기업군(BGs)의 시장점유율 제곱의 합으로 $\mathrm{H} 11$ 을 산정했다. $\mathrm{HI1}$ 값은 업체 수를 고려하지 않은 기업군(9 bgs 를 $3 \mathrm{BGs}$ 로 축약)별 업종(BTs)수인 8 개 업종군이고, 그 관측치 제곱의 합이다. $\mathrm{HII}$ 경우 소기업군의 값이 대기업군에 비해 상대적으로 높은 것은 소기업군내의 특정 업체의 시장지배력이 높은 것이 아니고, 업체 수를 고려하지 않은 단순 시장점유율 제곱의 합이기 때문이다. 이는 단순히 소기업군이 점유한 시장의 규모가 큰 것으로 해석될 수 있다. $\mathrm{MI} 1$ 값으로 판단할 경우도 $\mathrm{MC1}$ 과 $\mathrm{MC2}$ 의 분석과 동일하게 소기업군은 $\mathrm{FCB}, \mathrm{ARM}$, $\mathrm{FBT}, \mathrm{CME}$ 에서 그 값이 1,200 이상으로 타 도매업종 보다 시장규모 측면에서 가능성이 있는 것으로 분석된다. 반면에 도매 업종별 기업군별 업체 수를 반영하여 산정한 $H \mathbb{2}$ 경우 대기업군이 소기업군보다 상대적으로 높게 나타나는데, 이는 대기업군내 소수 업체의 시장지배력이 상대적으로 큰 것으로 분석할 수 있다. $\mathrm{HI} 1$ 과 $\mathrm{HD}$ 결과를 결합해 보면 도매시장내 소기업군의 시장은 충분히 확보되어 
있으나 소기업군내 업체간 경쟁이 치열한 것으로 분석되고, 대기업군은 그들이 점유한 시장을 소수의 기업이 지배하는 것으로 판단된다.

Table 6: Wholesale Market Power

\begin{tabular}{|c|r|r|r|r|r|r|}
\hline \multirow{2}{*}{$\begin{array}{c}\text { WS Biz. } \\
\text { Types }\end{array}$} & \multicolumn{2}{|c|}{ HI1 by Biz. Groups } & \multicolumn{2}{|c|}{ HI2 by Biz. Groups } \\
\cline { 2 - 8 } & \multicolumn{1}{c|}{ SBG } & \multicolumn{1}{c|}{ MBG } & \multicolumn{1}{c|}{ LBG } & \multicolumn{1}{c|}{ SBG } & \multicolumn{1}{c|}{ MBG } & \multicolumn{1}{c|}{ LBG } \\
\hline WCT & 833.3 & 460.7 & 163.3 & 0.01 & 0.10 & 1.30 \\
\hline FCB & 1202.9 & 704.6 & 14.1 & 0.67 & 3.81 & 1.76 \\
\hline ARM & 1770.8 & 379.2 & 9.6 & 0.89 & 3.94 & 1.60 \\
\hline FBT & 1427.1 & 498.3 & 16.8 & 0.09 & 0.32 & 0.61 \\
\hline HHG & 411.9 & 630.3 & 264.5 & 0.03 & 0.64 & 4.38 \\
\hline MES & 798.1 & 566.5 & 111.9 & 0.06 & 0.56 & 2.87 \\
\hline CME & 2235.0 & 299.5 & 2.3 & 0.28 & 0.70 & 0.32 \\
\hline OSW & 976.6 & 500.7 & 139.3 & 0.10 & 0.68 & 10.46 \\
\hline NSG & 14.2 & 37.1 & 4611.1 & 0.04 & 0.82 & 404.5 \\
\hline
\end{tabular}

Note: HI1 $=\Sigma(\mathrm{ms} \text { of bgs })^{2}$ by BGs and BTs

$\mathrm{HI} 2=\Sigma\left((\mathrm{ms} / \mathrm{co} \text { of } \mathrm{bgs})^{2} \mathrm{xco}\right)$ by BGs and BTs

\section{3. 연구방법}

\section{1. 연구대상}

도매업 성과분석을 위하여 도매업종과 기업군별로 시장점유율, 매출수익율 그리고 노동생산성의 평균차이를 분산분석으로 통계적 유의성을 검정한다. 또한, 이들 변수를 종속변수로 하고 영향을 미치는 독립변수들의 통계적 유의성을 회귀분석(Kim, 2010; Kwak, 2019)으로 검정하고 그 의미와 정책적 활용 가능성을 찾아보고자 한다.

\section{2. 가설과 검정방법}

\subsection{1. 가설}

가설 1: 사업규모별 기업군에 따라 시장점유율, 매출수익율, 노동생산성에 차이가 있다.

가설 2: 도매업종에 따라 시장점유율, 매출수익율, 노동생산성에 차이가 있다.

가설 3: 시장점유율은 사업체비중, 종사자비중, 사업규모, 고용규모, 업종에 따라 영향을 받는다.

가설 4: 매출수익율은 사업체비중, 종사자비중, 사업규모, 고용규모, 업종에 따라 영향을 받는다.

가설 5: 노동생산성은 사업체비중, 종사자비중, 사업규모, 고용규모, 업종에 따라 영향을 받는다.

\subsection{2 분석모형과 통계자료}

도매업 성과지표(MS, SPR, LP)에 대한 기업군(BGS), 도매업종(BTS)간의 차이를 분석하고, 이들 성과지표를 종속변수로 하고 산업구조(CW, EW) 및 업체구조(SC, SE) 그리고 업종간 차이(Dummies)를 독립변수하는 분석모형을 아래와 같이 구성한다. 실증분석을 위해 통계청의 2015 경제총조사 자료(KOSTAT, Economic census 2015, http://uww.kosis.kr)와 통계분석패키지 SPSS 18.0 을 사용하여 분산분석과 회귀분석으로 가설들의 검정을 시도하였다 (Khudadad, Tahir, \& Jan, 2018).

$$
\begin{aligned}
W P I_{m}= & C O_{m}+\alpha_{i} \sum_{i=1}^{2} I S_{i}+\beta_{j} \sum_{j=1}^{2} C I_{j} \\
& +\gamma_{k} \sum_{k=1}^{8} D V_{k}+e_{m}
\end{aligned}
$$

Where, $m=\mathrm{MS}$, SPR, LP; $i=\mathrm{CW}, \mathrm{EW} ; j=\mathrm{SC}, \mathrm{SE}$;

$$
k=\text { dummy } 1 \text {....dummy } 8
$$

Co: constant; $\alpha, \beta, \gamma$ : estimated coefficients;

$$
e \text { : error term }
$$

\begin{tabular}{|c|c|c|}
\hline Classification & Variables & Definitions \\
\hline \multirow{3}{*}{$\begin{array}{l}\text { Dependent } \\
\text { variables }\end{array}$} & Market share (MS) & sales volume / $\Sigma$ sales volume \\
\hline & Sale-profit ratio (SPR) & profit / sales volume \\
\hline & Labor productivity (LP) & $\begin{array}{l}\text { sales volume / number of } \\
\text { workers }\end{array}$ \\
\hline \multirow{5}{*}{$\begin{array}{l}\text { Independent } \\
\text { variables }\end{array}$} & $\begin{array}{l}\text { Company \# weight } \\
\text { (CW) }\end{array}$ & $\begin{array}{c}\Sigma \text { company \# in BG } / \Sigma \\
\text { company \# in wholesale } \\
\text { industry }\end{array}$ \\
\hline & $\begin{array}{l}\text { Employment \# weight } \\
\text { (EW) }\end{array}$ & $\begin{array}{l}\Sigma \text { employment \# in BG } / \Sigma \\
\text { employment \# in wholesale } \\
\text { industry }\end{array}$ \\
\hline & Size of company (SC) & $\begin{array}{l}\text { total sales volume / \# of } \\
\text { companies }\end{array}$ \\
\hline & $\begin{array}{l}\text { Size of employment } \\
\text { (SE) }\end{array}$ & $\begin{array}{l}\text { employment level scaled from } \\
1 \text { to } 9\end{array}$ \\
\hline & Dummies (1-8): BTs & $\begin{array}{l}\text { FCB, ARM, FBT, HHG, MES, } \\
\text { CME, OSW, NSG }\end{array}$ \\
\hline
\end{tabular}

WPI : Wholesale Performance Index

Table 7: Variables in Regression Analysis

\begin{tabular}{|c|c|c|}
\hline 원분산분석의 & 결과에 & 사업규모별 \\
\hline 시장점유율은 & 통계적으로 & 유의미하게 \\
\hline
\end{tabular}

\section{4. 연구결과분석}

\section{1. 일원분산분석 결과}


대기업군(BBG)보다 크게 나타나고 있다. 소기업군과 중기업군, 중기업군과 대기업군 사이에는 차이가 없는 것으로 분석되었다. 도매업종(BTs)간에는 시장점유율의 차이에 대한 영의 가설을 모두 채택함으로 차이가 없는 것으로 분석되었다.

Table 8: One-way ANOVA for Market Share

\begin{tabular}{|c|c|c|c|c|}
\hline \multicolumn{2}{|c|}{ WS Biz. Group } & \multicolumn{3}{|c|}{ Multiple comparison-LSD } \\
\hline (I) & $(\mathbf{J})$ & Avg. diff. (I-J) & S.E. & $\begin{array}{c}\text { Significance } \\
\text { probability }\end{array}$ \\
\hline SBG & LBG & $.0719^{* *}$ & .0333 & .035 \\
\hline
\end{tabular}

Note: ANOVA F-stat: $2.042^{*}$, Levene-stat: $0.480,{ }^{*}(\mathrm{p}<0.1), * *(\mathrm{p}<0.05)$.

매출수익율(SPR)은 기업군간에는 차이가 없는 것으로, 업종간에는 일부분 차이가 있는 것으로 나타났다. FCB, $\mathrm{HHG}, \mathrm{CME}$ 등의 업종들이 OSW 와 NSG 업종보다 매출수익율이 상대적으로 다소 높은 것으로 분석되었고, ARM 업종은 CME 업종보다 SPR 이 다소 낮은 것으로 나타났다.

Table 9: One-way ANOVA for Sales-Profit Rate

\begin{tabular}{|c|c|c|c|c|}
\hline \multicolumn{2}{|c|}{ WS Biz. Type } & \multicolumn{3}{c|}{ Multiple comparison-LSD } \\
\hline \multirow{2}{*}{$(\mathbf{I})$} & $(\mathbf{J})$ & Avg. diff. (I-J) & S.E. & $\begin{array}{c}\text { Significance } \\
\text { probability }\end{array}$ \\
\hline \multirow{2}{*}{ FCB } & OSW & $.0239^{* *}$ & .0115 & .043 \\
\cline { 2 - 5 } & NSG & $.0271^{* *}$ & .0115 & .022 \\
\hline \multirow{2}{*}{ ARM } & CME & $-.0240^{* *}$ & .0119 & .048 \\
\hline HHG & NSG & $.0217^{* *}$ & .0108 & .049 \\
\hline \multirow{2}{*}{ CME } & OSW & $.0288^{* *}$ & .0111 & .012 \\
\cline { 2 - 5 } & NSG & $.0320^{* * *}$ & .0111 & .006 \\
\hline
\end{tabular}

Note: ANOVA F-stat: $2.042^{*}$, Levene-stat: $0.480, *(\mathrm{p}<0.1), * *(\mathrm{p}<0.05)$.

노동생산성(IP)은 대기업군이 소기업군과 중기업군에 비해 높으나 소기업군과 중기업군에는 차이가 없는 것으로 분석되었다. 도매업종간의 노동생산성은 OSW 와 NSG 업종이 여타의 업종에 비해 높으나 그들 사이와 그리고 여타 업종간의 $\mathrm{LP}$ 에는 차이가 없는 것으로 분석되었다.

Table 10: One-way ANOVA for Labor Productivity

\begin{tabular}{|c|c|c|c|c|c|}
\hline \multicolumn{3}{|c|}{ Classification } & \multicolumn{3}{|c|}{ Multiple comparison-LSD } \\
\hline L. $P$. & (I) & (J) & Ave. diff.(I-J) & S.E. & Stats \\
\hline \multirow{2}{*}{$\begin{array}{l}\text { WS } \\
\text { BGs }\end{array}$} & SBG & LBG & $-1,086.3^{* * *}$ & 271.6 & \multirow{2}{*}{$\begin{array}{c}\text { F-stat: } \\
8.391 * * * \\
\text { Levene-stat: } \\
2.632^{* * *}\end{array}$} \\
\hline & MBG & LBG & $-805.9 * * *$ & 271.6 & \\
\hline \multirow{3}{*}{$\begin{array}{l}\text { WS } \\
\text { BTs }\end{array}$} & ECR & OSW & $-1,164.9 * *$ & 441.7 & \multirow{3}{*}{$\begin{array}{c}\text { F-stat: } \\
3.323^{* * *} \\
\text { Levene-stat: } \\
7.356^{* * *}\end{array}$} \\
\hline & $\Gamma C D$ & NSG & $-1,201.9 * * *$ & 441.7 & \\
\hline & ARM & OSW & $-1,171.3 * * *$ & 441.7 & \\
\hline
\end{tabular}

\begin{tabular}{|c|c|c|c|}
\hline & NSG & $-1,208.4 * * *$ & 441.7 \\
\hline \multirow{2}{*}{ FBT } & OSW & $-1,154.3^{* * *}$ & 413.2 \\
\hline & NSG & $-1,191.4 * * *$ & 413.2 \\
\hline \multirow{2}{*}{ HHG } & OSW & $-1,099.6^{* * *}$ & 413.2 \\
\hline & NSG & $-1,136.7 * * *$ & 413.2 \\
\hline \multirow{2}{*}{ MES } & OSW & $-1,057.9^{* *}$ & 413.2 \\
\hline & NSG & $-1,094.9 * * *$ & 413.2 \\
\hline \multirow{2}{*}{ CME } & OSW & $-1,222.8 * * *$ & 425.9 \\
\hline & NSG & $-1,259.9^{* * *}$ & 425.9 \\
\hline
\end{tabular}

Note: $* *(\mathrm{p}<0.05), * * *(\mathrm{p}<0.01)$.

일원 분산분석의 결과를 보면 도매시장 내 시장점유율로 보아 중소기업군과 대기업군이 함께 상존하는 모습을 보이고 있고, 매출수익율에도 그들 간의 큰 차이가 없으나 중소업체는 노동생산성을 제고해야 하는 문제를 않고 있는 것으로 나타난다.

\section{2. 이원분산분석 결과}

이원분산분석 결과를 보면 기업군(BGs)의 주 효과와 상호작용효과(BG x BT)는 시장점유율(MS)에 통계적으로 유의미하게 영향을 미치는 것으로 나타나나, 업종의 경우 영향을 미치지 못하는 것으로 분석되었다. 반면에 매출수익율(SPR)은 업종간(BTs)간에는 차이가 있으나 기업군과 상호작용에 따라 영향을 받지 않는 것으로 분석되었다. 또한 노동생산성(P)의 경우는 기업군(BGs), 업종(BTs) 그리고 상호작용(BG $\times$ BT) 모두에게서 영향을 받아 그들간의 노동생산성에 차이가 있는 것으로 해석된다.

Table 11: Two-way ANOVA for Market Result

\begin{tabular}{|c|c|c|c|c|c|c|}
\hline $\begin{array}{c}\text { D. } \\
\text { Variables }\end{array}$ & \begin{tabular}{|c|} 
S. of \\
Variation
\end{tabular} & SS & d.f. & MS & $\mathbf{F}$ & Stats \\
\hline \multirow{4}{*}{ MS } & BG & .069 & 2 & .034 & $3.107 *$ & \multirow{4}{*}{$\begin{array}{c}\mathrm{R}^{2}=0.414 \\
\text { adj- } \\
\mathrm{R}^{2}=0.101\end{array}$} \\
\hline & BT & .000 & 7 & $6.8 \mathrm{E}-5$ & .006 & \\
\hline & $\mathrm{BG} \times \mathrm{BT}$ & .272 & 14 & .019 & $1.757 *$ & \\
\hline & C. Total & .811 & 66 & & & \\
\hline \multirow{4}{*}{ SPR } & $\mathrm{BG}$ & .001 & 2 & .001 & 1.232 & \multirow{4}{*}{$\begin{array}{c}\mathrm{R}^{2}=0.468 \\
\text { adj- } \mathrm{R}^{2}=0.184\end{array}$} \\
\hline & BT & .009 & 7 & .001 & $2.775^{*}$ & \\
\hline & $\mathrm{BG} \times \mathrm{BT}$ & .009 & 14 & .001 & 1.384 & \\
\hline & C. Total & .038 & 66 & & & \\
\hline \multirow{4}{*}{ LP } & $\mathrm{BG}$ & 7.3E6 & 2 & $3.7 \mathrm{E} 6$ & $9.612 * * *$ & \multirow{4}{*}{$\begin{array}{c}\mathrm{R}^{2}=0.740 \\
\operatorname{adj}-\mathrm{R}^{2}=0.601\end{array}$} \\
\hline & BT & $1.7 \mathrm{E} 7$ & 7 & $2.5 \mathrm{E} 6$ & $6.493 * * *$ & \\
\hline & $\mathrm{BG} \times \mathrm{BT}$ & $1.8 \mathrm{E} 7$ & 14 & $1.3 \mathrm{E} 6$ & $3.289 * * *$ & \\
\hline & C. Total & $6.3 \mathrm{E} 7$ & 66 & & & \\
\hline
\end{tabular}

Note: $*(\mathrm{p}<0.1), * *(\mathrm{p}<0.05), * * *(\mathrm{p}<0.01)$. 


\section{3. 회귀분석 결과}

시장점유율(MS)에 대한 회귀분석 결과 고용비중(EW)과 업체규모(SC)는 양(+)의 효과를 보이고, 업체비중(CW)과 고용규모(SE)는 음(-)의 효과를 나타내고 있다. 이는 기업군의 고용비중이 크거나 기업군내 개별 업체의 규모가 큰 경우에 시장점유율에 긍정적인 효과를 가진다. 반면에 기업군의 업체비중이 높거나 기업군내 개별업체의 고용규모가 큰 경우 과다한 경쟁과 고용의 비효율성으로 시장점유율에 부정적인 효과를 나타내는 것으로 분석된다. 더미변수인 업종의 영향력은 OSW 와 NSG 업종을 제외하고 모든 업종이 통계적으로 유의미하게 나타나는데, 이는 각각의 업종이 여타의 업종에 비하여 시장점유율에 있어서 긍정적인 위치에 있는 것으로 해석될 수 있다.

Table 12: Regression Analysis Results

\begin{tabular}{|c|c|c|c|c|c|c|}
\hline Variables & \multicolumn{2}{|c|}{ MS } & \multicolumn{2}{c|}{ SPR } & \multicolumn{2}{c|}{ LP } \\
\hline Indep. & Coeff. & t-Stat & Coeff. & t-Stat & Coeff. & t-Stat \\
\hline Const. & .063 & $3.72^{* * *}$ & .049 & $12.61^{* * *}$ & 393.559 & $3.13^{* * *}$ \\
\hline CW & -.400 & $-10.12^{* * *}$ & .087 & $4.68^{* * *}$ & - & - \\
\hline EW & 1.093 & $22.28^{* * *}$ & -.136 & $-4.50^{* * *}$ & - & - \\
\hline SC & $1.13 \mathrm{E}-7$ & $9.35^{* * *}$ & - & - & .001 & $6.65 * *$ \\
\hline SE & -.015 & $-5.40^{* * *}$ & - & - & - & - \\
\hline D1(FCB) & .041 & $2.96^{* * *}$ & .021 & $2.66^{* * *}$ & -616.705 & $-3.40^{* * *}$ \\
\hline D2(ARM) & .040 & $2.85^{* * *}$ & - & - & -746.582 & $-4.10^{* * *}$ \\
\hline D3(FBT) & .039 & $3.04^{* * *}$ & - & - & -648.880 & $-3.91^{* * *}$ \\
\hline D4(HHG) & .036 & $2.86^{* * *}$ & .014 & $2.04 * *$ & -708.326 & $-4.28^{* * *}$ \\
\hline D5(MES) & .035 & $2.79^{* * *}$ & - & - & -702.310 & $-4.24^{* * *}$ \\
\hline D6(CME) & .039 & $2.94^{* * *}$ & .025 & $3.40^{* * *}$ & -724.022 & $-4.17^{* * *}$ \\
\hline D7(OSW) & - & - & - & - & - & - \\
\hline D8(NSG) & - & - & - & - & - & - \\
\hline F-stat. & \multicolumn{2}{|c|}{85.873} & $8.453^{* * *}$ & $44.004 * * *$ \\
\hline Adj-R ${ }^{2}$ & \multicolumn{2}{|c|}{$.928, * * *$} & \multicolumn{2}{|c|}{.361} & \multicolumn{2}{|c|}{.839} \\
\hline
\end{tabular}

Note: $*(\mathrm{p}<0.1), * *(\mathrm{p}<0.05),{ }^{* * *}(\mathrm{p}<0.01)$.

매출이익율(SPR)의 경우는 기업군의 업체비중(CW)과 고용비중(EW)이 통계적으로 유의미한데 업체비중은 양(+), 종사자비중은 음(-) 관계로 나타난다. 주로 소기업군(SBG)의 업체비중과 종사자비중이 높은데, 이는 소기업군의 업체들이 단순 대량 판매를 위한 매출보다는 인적 서비스를 가미한 수익을 추구하고, 또한 인적 서비스로 발생하는 기회비용이 단순 노동생산성의 비효율성으로 나타나는 것으로 판단된다. 도매업종의 영향력은 $\mathrm{FCB}, \mathrm{HHG}, \mathrm{CME}$ 업종이 타 도매업종에 비해 매출수익율에 긍정적인 업종으로 분석된다.
노동생산성( $(\mathrm{P})$ 의 경우 기업군내 개별 업체의 규모가 클수록 긍정적인 것으로 나타난다. 이는 대기업군의 특징인데 노동생산성은 대기업군이 상대적으로 높은 것으로 분석된다. 소기업군내 개별 업체는 사업의 규모를 키우고 고용의 효율성을 제고함으로 노동생산성을 증가시킬 수 있을 것으로 판단된다. 업종의 영향력은 OSW 와 NSG 업종을 제외한 모든 업종이 노동생산성과의 관계에서 통계적으로 유의미하나 음(-)의 관계로 나타나 이 업종들이 타 업종에 비해 노동생산성에 있어서 부정적인 위치에 있는 것으로 분석된다.

\section{5. 결론 및 향후 연구}

\section{1. 결론}

시장점유율 관점에서 중소기업군과 대기업군이 도매시장내 함께 상존하는 모습을 보이고 있고, 매출수익율에도 그들 대·중소 업체간에 큰 차이가 없으나, 중소업체는 비효율적인 노동생산성을 제고해야 하는 문제점이 있는 것으로 분석된다. 이는 소기업군의 높은 업체수비중과 종사자비중은 업체간 과다 경쟁과 낮은 노동생산성의 원인이 되고 있다 그러므로 소기업군은 업체 수에 있어 구조조정이 필요하고, 개별 업체의 사업규모를 키워 고용의 효율성을 제고할 필요가 있다. 소기업군은 시장집중도와 시장지배력 측면에서는 $\mathrm{FCB}, \mathrm{ARM}, \mathrm{FBT}$, $\mathrm{CME}$ 업종에서 가능성을 찾아 볼 수 있다. 반면에 소기업군의 업체들이 단순 판매를 통한 매출보다는 인적서비스를 가미한 높은 수익을 추구하는 점에 목표를 둘 경우 HHG, MES, CME 업종에서 매출수익율이 $5 \%$ 를 상회할 뿐만 아니라 MES, CME, 그리고 OSW 업종에서는 타 업종에 비해 상대적으로 고용인당 수익이 다소 높은 편으로 나타나 경쟁력이 있다는 점도 관심을 둘 필요가 있다.

\section{2. 정책적 제언}

도매업의 대·중소 동반성장을 기반으로 하는 균형적 발전은 경제성장에도 긍정적인 영향을 미칠 것으로 판단된다 $(\mathrm{He}, 2019)$. 이를 위해서는 각 기업군내 업체들이 경영상 효율성 추구와 경쟁력 있는 차별적 업태로 혁신해 가야 한다. 뿐만 아니라 특정 업체 또는 기업군의 시장지배력을 완화하고, 기업군간의 구조적인 차이를 극복할 수 있도록 정부가 생계형 혹은 중소도매업 적합업종 지정과 같은 법·제도를 통해 시장에 개입함도 그 무엇보다도 중요하다. 건전한 도매업 육성을 위한 정부정책 목표는 성장을 주도하는 한 기업군의 시장지배를 지양하고, 도매시장내 대·중소기업의 상생기반을 마련하고 균형적 발전을 위한 역할을 분담토록 하는 것이다 (Kim \& Song, 2019). 대형 도매기업으로 
하여금 유통구조 변화에 전략적 혁신을 주도하도록 하며, 전통적인 중소도매업체로 하여금 유통환경 변화에 스스로 진화해 갈 수 있도록 벤치마킹의 성공사례를 제공하고 (Mackeown. 2007), 더불어 유통경로상의 협업시스템 구축지원도 필요하다 (Quinn \& Murray, 2005; Feng, Song, Jiao, \& Mu, 2012).

\section{3. 향후연구}

분석한 통계자료는 5 년마다 조사되는 통계청의 경제총조사 자료를 사용했다. 향후 2020 년 자료를 비교하여 분석하면 도매시장의 구조변화에 대한 새로운 결과를 도출할 수 있을 것으로 생각된다. 뿐만 아니라 소기업군에 긍정적인 세분류상의 도매업종을 선택하여 세세분류 도매업종의 시장구조와 경쟁력 관점에서 소기업군에 유리한 업종을 발굴해 보는 것도 필요할 것으로 보인다.

\section{References}

Cetin, T., \& Eryigit, K. (2013). The Economic Effects of Government Regulation: Evidence from the New York Taxicab Market. Transport Policy, 25, 169-177.

Choi, D., \& Suh, G. (2017). A Study on the Effects of Small Business Management Result by the Korean Government: Focus on SEMAS. East Asian Journal of Business Management, 7(3), 33-43.

Feng, J., Song, J., Jiao, W., \& Mu, W. (2012). Grape distribution efficiency in wholesale market, Beijing, China. Journal of Food, Agriculture \& Environment, 10(1), 67-70.

Garrido, E., \& Whalley, J. (2013). Competition in Wholesale Markets: Do MNOs Compete to Host MVNOs? Telecommunication Policy, 37, 1124-1141.

He, Y. (2019). A Study on the Mutual Effect between Small \& Medium-sized Enterprises and Economic Growth: Evidence from Alibaba Group and City of Hangzhou. The Journal of Business Economics and Environmental Studies, 9(2), 27-34.

Im, K., Kim, H., \& Yang, H. (2017). The Effectiveness on the Perception of Service Quality in MRO Transactions. East Asian Journal of Business Management, 7(4), 11-25.

Khudadad, S., Tahir, M., \& Jan G. (2018). The Comparative Financial Performance of Outsourcing and Vertical Integrated Corporations. East Asian Journal of Business Management, 8(3), 23-31.

Kim, D., \& Kwon, S. (2013). A Study on the Korea Distribution Promotion Policy and Adjustment Policy. Journal of Distribution Science, 11(4), 89-97.

Kim, D., \& Ryu, S. (2014). An Analysis of the Effects of Large- scale Retailer Operations on Agriculture and Fisheries. Journal of Distribution Science, 12(2), 73-79.

Kim, K. (2010). Applications of statistical analysis in social science. Seoul, Korea: B\&M Books.

Kim, K., \& Song, S. (2019). A Study on the Effect of Win-win Growth Policies on Sustainable Supply Chain and Logistics Management in South Korea. International Journal of Industrial Distribution \& Business, 10(12), 7-14.

KOSTAT (2015). Economic census 2015. Korean Statistical Information Service, Retrieved May 22, 2019, from http://www.kosis.kr.

Kwak, K. (2019). Statistical Data Analysis with SPSS. Seoul, Korea: CRBOOKS.

Lee, C. (2019). The Effects of Traditional Market Support Projects and Competition Intensity of Stores on Store Sales and Number of Visitors. Journal of Distribution Science, 17(3), 97-105.

Lee, J., \& Lim, I. (2020). A Comparative Study on Convergence of IT, BT and NT: Focusing on Patent Data. Journal of Asian Finance, Economics and Business, 7(1), 239-247.

Mackeown, H. (2007). Wholesaling and Wholesaling Research: A Practitioner's Viewpoint. International Review of Retail Distribution and Consumer Research, 17(4), 413-422.

Ministry of SMEs and Startups (2018). Special Act on the Designation of a suitable Business for Living Type. Retrieved May 22, 2019, from https://www.mss.go.kr/site/eng/ex/bbs/ View.do? cbIdx $=244 \&$ bcIdx $=10000168$

Park, H., Kim, J., \& Yu, J. (2018). Effect of Environmental Dynamics on the Business Performance of Franchise Distribution Industry. Journal of Distribution Science, 16(3), 59-68.

Pirog, S., \& Smith, S. (1996). A Market-Orientation Approach to Identifying Structural Change in Wholesaling. Journal of Marketing Channels, 5(1), 37-58.

Quinn, J., \& Leavy, B. (2005). The Drivers of Industry Evolution: A Study of Irish Wholesaling. Journal of Marketing Channels, 13(1), 37-62.

Quinn, J., \& Murray, J. (2005). The Drivers of Channel Evolution: A Wholesaling Perspective. International Review of Retail, Distribution \& Consumer Research, 15(1), 3-25.

Shukla, U., \& Thampy, A. (2011). Analysis of Competition and Market Power in Wholesale Electricity Market in India. Energy Policy, 39, 2699-2710.

Won, J. (2010). A Study of Wholesale Business Status and Development Plan in Korea. General Economic Research, 406, Korea Chamber of Commerce and Industry.

Yang, H., \& Ju, Y. (2011). Positive integration of the franchise system: A new perspective on leadership, followership, trust and group efficacy. East Asian Journal of Business Management, $1(1), 5-8$.

Yoon, S., Song, S., \& Kang, M. (2020). The Growth and Change of Korean Cosmetics Market in Distribution Structure. Journal of Distribution Science, 18(1), 5-13. 